\title{
Chapter 01
}

\section{A New Business Model}

- Using Platforms for Play

- Various Definitions of Platform

- Traditional Platforms

- Is a Department Store a Platform?

- Economic Perspectives on Platforms

- Platform: A New Business Model

- Insist on Piping or Transform into Platform? 
Is it possible to create 300,000 new jobs and to make

$\$ 1$ billion simply by drinking and dancing for 4 or

5 days? It sounds ridiculous, but it happens at

Rio Carnival. Including indirect income from broadcasting rights and other sources, the Rio Carnival, which is the world's largest carnival, generates $\$ 3.2$ billion annually for the Brazilian economy. The Carnival is a type of platform, a playground where people have fun; it brings enormous financial benefits. Let us examine the use of platforms for fun and profit-making. 


\section{Using Platforms for Play}

The platform is not only the interface connecting various business participants, but it is also the location of the transaction. Having a viable platform strategy creates new businesses by gathering many related businesses in one place. In the sense that it requires cooperation from many business actors, a platform strategy is opposite to a stand-alone strategy. For example, the Rio Carnival attracts tourists by offering new attractions in the parades every year through a competition among many Samba schools.

Platform strategy leaders create values and resolve issues when they interface with business partners. During this process, the platform becomes active, its members get more organized, and an ecosystem is created through the interface experience. A platform consists of a group of members in a business ecosystem in which members can play around. Using this definition, we can understand the offline platform as a physical space where people move around, and the online platform as a space in which content is located and software is utilized. A platform also consists of a platformer. The main role of the platformer is to provide a good business environment, a playground in which sellers, buyers, and community members can interact. Constant maintenance of the playground is also the responsibility of the platformer.

When serendipity occurs during the interface process, more people come to the platform. If a star is born there, the company that owns the playground also succeeds. This is the benefit of platform strategy. Good platform leadership is essential to the process of creating an industrial ecosystem where the active participation of all members produces profit. Platform leaders are responsible for supporting the health of an ecosystem that engages on their platform.

Platform strategy is utilized especially in the IT industry. The term "platform" in the IT industry refers to the hardware or software which forms the basis of the computer system on which people can develop various programs. For example, the main frame is the platform on which large-scale databases can be built, and operating 
systems such as Windows, UNIX, and LINUX are platforms where relevant software can be operated.

While it is true that the IT industry is the major industry in which the concept of platform is used, it is not the only one. Platform has played an important role during revolutionary times. Platforms at train stations built by George Stephenson at the beginning of the $19^{\text {th }}$ century led to the Industrial Revolution. Also, Steve Jobs pioneered the Smart Revolution by creating platforms such as the iPod and iPhone.

The Smart Era has begun, and it encompasses far more than its predecessor, the Digital Era. Therefore, the significance of platform strategy is ever-increasing. Various platforms appropriated to the Smart Era must be developed. New IT platforms will accelerate the Smart Revolution, leading our society into this new era.

\section{Various Definitions of Platform}

Although many companies have declared themselves to be the platform of their industries or have claimed to be platform leaders in their fields, it seems difficult to get a clear definition of the word "platform". In fact, it may be impossible to have a conclusive definition with so many different perspectives on the meaning of "platform".

Major definitions of platform

\begin{tabular}{cc}
\hline $\begin{array}{c}\text { Meyer \& Lehnerd (1997) } \\
\text { Company Platform }\end{array}$ & $\begin{array}{c}\text { A set of assets organized in a common structure } \\
\text { from which a company can efficiently develop and } \\
\text { produce a stream of derivative products }\end{array}$ \\
$\begin{array}{c}\text { Gawer \& Cusumano (2002) } \\
\text { Industry Platform }\end{array}$ & $\begin{array}{c}\text { Products, services, or technologies developed by one } \\
\text { or more firms, and which serve as foundations } \\
\text { upon which a larger number of firms can build } \\
\text { further complementary innovations, in the form } \\
\text { of specific products, related services, or } \\
\text { component technologies }\end{array}$ \\
Aansiti \& Levien (2004) A & $\begin{array}{l}\text { set of solutions to problems that is made available } \\
\text { to the members of the ecosystem through a set of } \\
\text { access points and interfaces }\end{array}$ \\
\hline
\end{tabular}

(Continued) 
(Continued)

\begin{tabular}{lc}
\hline $\begin{array}{l}\text { Rochet \& Tirole (2003) } \\
\text { Two-sided Market (TSM) }\end{array}$ & $\begin{array}{c}\text { Markets that "get both sides on board" by charging } \\
\text { more to one set of customers in order to increase } \\
\text { demand by others }\end{array}$ \\
$\begin{array}{l}\text { Evans (2003) } \\
\text { Bwo-sided Platform } \\
\text { (TSP) }\end{array}$ & $\begin{array}{l}\text { cust enses that create value by providing products } \\
\text { exchange value }\end{array}$ \\
$\begin{array}{l}\text { Haigu (2007) } \\
\text { Multi-sided Platform } \\
\text { (MSP) }\end{array}$ & $\begin{array}{l}\text { An organization that creates value primarily by } \\
\text { enabling direct interactions between two or more } \\
\text { distinct types of affiliated customers }\end{array}$ \\
\hline
\end{tabular}

In this chapter, we examine some of the major definitions and their trends to improve our understanding of the platform.

Many companies use the word, "platform," as they develop new products through gradual innovations based on existing components or technologies. From this point of view, platform is defined as a subordinate system, an interface which, when combined as a common structure, makes efficient development and production possible. Such a platform is called a "product platform" or "inner platform". A company can respond to the needs of customers by combining components in new ways or by adding some components to previous combinations. A good platform strategy encompasses the development of a basic model that results in various products with some changes in component combinations.

A product platform has various advantages, including reduced costs, increased efficiency due to recycling the design and use of common parts, and flexibility in product design. Gawer and Cusumano (2002) and Ianciti and Levien (2004) expanded the concept of the product platform to the industrial context. They described how the basic components or technologies (solutions) from one company are made available to other companies, forming a community of participating companies that innovate based on this platform. The level of openness depends on the area. Accessibility of the interface information, freedom to utilize the platform, and the cost of the license and royalties determine the openness of the platform. 
An industrial platform ${ }^{1}$ expedites the innovation of complementary goods. As an example, Windows, which is the operating system of Microsoft, is a platform for which many complementary programs have been developed. As more complementary goods are developed through innovation, the value of the platform is strengthened along with its connection to its participants. As a result, as the platform grows, rivals or newcomers have more difficulty in disconnecting the participants from the platform. In addition, increased complementary goods becomes another barrier. One good example is that many people do not abandon the Windows operating system, even though other companies have developed excellent operating systems. Therefore, the downside of an industrial platform is that it often eliminates competition in the market.

The term "platform" has been used for two-sided markets or multi-sided markets. These economic terms are described as follows. Two-sided markets connect two groups benefiting from the network, and multi-sided markets connect more than two groups. In these markets, a company creates value by becoming or providing a platform where two or more customers can get together. Customers come to need one another in various ways, and they depend on the platform as an intermediary. Examples of two-sided markets include the credit card (card user and stores), computer operating systems (users and developers), phone directory (advertisers and customers), video games (gamers and game developers), job search websites (employers and job seekers), and search engines (advertisers and users).

The two-sided market has different characteristics from the merchant market. First, in the two-sided market, the platform offers interaction between two different groups. Secondly, the

\footnotetext{
${ }^{1}$ Operating systems such as Windows and Linux; microprocessors such as Intel or ARM; the iPod, iPhone, iPad, iOS, and App stores of Apple; Google's search engine and Android's operating system; SNS such as Facebook and Twitter; video game consoles; and various other goods and technologies all play roles in the industrial platform.
} 
two-sided market allows two groups to have direct interplay. Thirdly, the two-sided market has indirect network effects (also called cross-network effects). As the number of participants increases, the value of the platform also increases. For example, store managers prefer to be affiliated with credit cards that have many users. Fourthly, the two-sided market has a unique pricing system. For example, to increase the size of the network, a certain group may be charged lower prices than the production cost, or they may be provided with a subsidy.

In this book, we examine the concept of the platform from the solution and two-sided market standpoints. The former emphasizes the approach to solutions, and the latter emphasizes the platform as a new market mechanism. These two standpoints differ in their emphasis on the value of the platform: either on the affiliated participants, or on the solutions it offers.

All businesses have customers or partners. The platform approach depends on how the business looks at them and what role the company chooses to take in the interplay between them. A business support organization or a student employment office at a college is a platform from the solution standpoint. In contrast, businesses offering a forum for interplay among customers, or an employment website are platforms from the two-sided market standpoint.

\section{Traditional Platforms}

The platform is not a new business model. Various types of platforms have been developed in the past. For instance, the newspaper is a platform connecting the reader and the advertiser, and the telephone directory is a platform connecting the user and the advertiser. Currency we use every day can also be understood as a platform connecting users and marketers. Among the various available currencies, the American dollar, the Euro, the Japanese Yen, and the British Pound are key global platforms (key currency). 
Comparison of platform approaches

\begin{tabular}{|c|c|}
\hline Solution Standpoints & Two-sided Market Standpoints \\
\hline $\begin{array}{l}\text { Product platform, industry platform, a } \\
\text { group of solutions }\end{array}$ & $\begin{array}{l}\text { Two-sided market, multi-sided market, } \\
\text { multi-side platform }\end{array}$ \\
\hline $\begin{array}{l}\text { Interested in the development of } \\
\text { attractive solutions }\end{array}$ & Interested in connections and matching \\
\hline Implicit consideration of users & Clear inclusion of users \\
\hline $\begin{array}{l}\text { Better business ecosystem makes } \\
\text { market successful }\end{array}$ & $\begin{array}{l}\text { Connection platforms between sellers } \\
\text { and buyers }\end{array}$ \\
\hline $\begin{array}{l}\text { All companies that provide solutions, } \\
\text { e.g. Walmart, discount stores, } \\
\text { franchises, Intel, global component } \\
\text { companies }\end{array}$ & $\begin{array}{l}\text { Newspaper, phone directory, } \\
\text { matchmaker } \\
\text { Credit card } \\
\text { Airport, train station, subway station, } \\
\text { bus terminal }\end{array}$ \\
\hline Meyer \& Lehnerd (1997) & Rochet \& Tirole (2003) \\
\hline $\begin{array}{l}\text { Gawer \& Cusumano (2002) } \\
\text { Iansiti \& Levien (2004) }\end{array}$ & Evans (2003), Haigu (2007) \\
\hline
\end{tabular}

\section{Credit Card}

A credit card is a payment platform which connects card holders and affiliated stores. For example, the Visa card exclusively connects Visa card owners and Visa card-affiliated stores. Therefore, the first focus for the Visa Company is membership, both for card holders and stores.

In a traditional market, every buyer has equal worth. However, a credit card is not worthwhile unless its membership exceeds a certain threshold. In economics terms, we talk about economies of scale. Consumers like credit cards that have many member stores, and stores prefer to accept cards that have many users. Credit card companies spend a lot of money in attracting new members and in providing various, optional services, because nearly half of their profits are generated from fees.

\section{Newspapers}

Among newspapers, we often notice a fierce competition to acquire readers by giving away all kinds of gifts. This competition occurs, 
because the newspaper is a platform. It differs from the credit card in that its potential readers rarely consider the number of subscribers or advertisers in their choice of newspaper. On the other hand, advertisers consider which newspaper has the largest number of readers, because they are interested in obtaining the widest possible effects of the advertisement. Therefore, newspapers take considerable pains to increase their readership.

Newspapers are often distributed free on the street. In the newspaper business, free distribution is a common way to increase readership. With free distribution, newspaper companies can claim that they have a large share of the market. No one talks about the Fair Trade Act regarding this practice, and the newspaper companies get more than enough compensation from the practice through advertisements. However, since the newspaper rating system started counting only regular paying subscribers, competition for subscribers has intensified, and all kinds of incentive programs have been initiated.

Free newspaper distribution has almost disappeared, as readers have started depending on their smartphones for their news. Newspaper platforms are being replaced by the new online platforms.

\section{Video Games}

Buyers of game consoles want to have fun and excitement through playing games. Game developers want to create games for popular game consoles (platforms). To make a game platform successful, a minimum number of games must be developed, and a sufficient number of users must play the game.

Big video game platforms such as Sony, Sega, and Nintendo have sources of profit other than the sales of game consoles. Their major profits come from royalties for use of their gaming platforms. Even when video game consoles are sold at less than the cost of production, these consoles become loss leaders. When users buy more consoles, a virtuous cycle develops in which users bring along developers, which continue to bring along users. The cycle continues as some of those new users seek to purchase new consoles. However, there have been many cases of failed game platforms despite excellent technologies. 
When a technology is too sophisticated, it becomes difficult to develop good quality games for it. This is why Microsoft chose the x86 and Windows platforms, which were familiar to game developers when the Xbox was launched in 2001.

In the video game industry, the key competitive elements are the price and the ease of use of the operating system. It is a different story when it comes to online or mobile games. First of all, game consoles are replaced by the platforms and operating systems of computers and smartphones. Even social network services (SNS) like WhatsApp act as platforms since users play games on them. This situation has changed the source of profit for game developers to advertisement or sales of game-related items.

\section{Matchmaking Business}

According to the Matrimonial Brokerage Management Act, matchmaking refers to counseling and arrangement for the purpose of marriage. Matchmakers earn their income from commission, fees, and other sources. About 1,500 matchmaking companies operate actively in Korea; among these, 4 or 5 big companies are leading the market, which is estimated to be around 150 million USD, according to the statistics at the end of 2019.

The matchmaking business can be considered as a platform which connects two different groups of men and women. Therefore, as we observed in the case of credit cards, newspapers, and video games, this platform becomes more attractive as the number of users increases. For instance, when a woman selects a matchmaking company, she may prefer a company with a large number of male members. Therefore, companies with a large number of male members will attract a greater number of female members, after which it will attract more men. The result is a virtuous cycle.

The ultimate purpose of a matchmaking company is marriage for its members. Therefore, matchmaking services require a balanced number of male and female members and a swift matching mechanism. Even if the matchmaking platform has a large pool of members, 
if the gender balance in its membership is not well maintained, business success is not guaranteed.

\section{Is a Department Store a Platform?}

A shopping mall, which has several stores in one building, is a typical platform. The more stores it has, and the more shoppers come to the building, the higher the value of the shopping mall. The question then arises, what about the department store? Is it a platform or not?

Unlike the department stores in the U.S or the U.K., which use the direct purchase method, Korean department stores utilize the specified purchase method. ${ }^{2}$ In Korea, $90 \%$ of department stores use the specified purchase method, and $90 \%$ of discount stores utilize the direct purchase method. Unlike in other countries, Korean department stores are not "retailers" which purchase goods and sell them to consumers. Rather, a Korean department store is a "rental business" which allows independent brands to open their shops in the building, taking a certain percentage of the sales as commission. Therefore, enterprises that have set up shop in the department store are basically tenants. From this perspective, we may conclude that department stores in Korea are platforms, not resellers.

\section{The Department Store as a Solution}

Department stores in Korea provide solutions for both business enterprises and shoppers. They provide the shopper with entertainment and various modes of consumption, and the enterprises operating within the store with reliability and a stable source of sales. Department stores also give to the stores opportunities to contact many customers, thereby reducing uncertainty. At the same time, due to the brand

\footnotetext{
${ }^{2} \mathrm{~A}$ method in which the department store purchases goods, but pays the supplier after the goods are sold. In this method, the department stores also charge a certain amount of commission to their suppliers. Also, they need not worry about inventory clearance.
} 
Platform elements of department stores

\begin{tabular}{ll}
\hline Distinction & Contents \\
\hline Hardware & Buildings, parking lots, rest areas, land \\
Software & Development of merchandising and complimentary goods \\
& Personal service from salespeople, card services, customer \\
& relationship management, delivery services \\
& Cultural and entertainment areas, food court \\
& Brand image, public relations, advertisement \\
\hline
\end{tabular}

value of the department store, business enterprises situated within it can increase the credibility of their own brands. Another benefit of opening a shop in a department store is that it is economical in terms of investment and maintenance costs, compared with having an independent store.

At a department store, shoppers get the benefit of convenience, as they can do various kinds of shopping in one place. In addition, they can enjoy the diverse experiences of dining, cultural events, and educational programs. In Korean department stores, the food and beverage services play a particularly important role in attracting customers (i.e., the food court, restaurants, and grocery corners) because many people come to a department store to enjoy good foods.

\section{The Department Store as a Two-Sided Market}

From the market point of view, department stores act as platforms for two-sided markets, connecting the shops and the shoppers. Department stores in Korea have many characteristics of shopping malls. Rather than making profit from reselling goods purchased externally, they make profit from commissions. There are certain sections in department stores that employ the direct purchase system, like the food market and some private brand shops. However, the main profit comes from the rent and commission they received from the shops. In this sense, it is a similar system to that of a shopping mall.

For example, if a customer who needs a suit comes to a department store in Korea, he goes to a shop which is a tenant in the 
building. In fact, the customer buys a suit from the shop, not from the department store. If the customer pays one million won, the money goes into the account of the department store first, after which the department store gives 660,000 won back to the shop. The department store owes the shop this amount, since it takes a commission of $34 \%$ of one million won. According to the report of the Korean Fair Trade Commission in 2014, the average department store commission rate is $28 \%$ (shirts and ties $33.8 \%$, children's items $31.9 \%$, leisure items $31.5 \%$, books and music $13.7 \%$, and digital items $14.2 \%)$.

The department store makes various efforts to increase its competitiveness as a platform. The first priorities are location and merchandising. The entertainment and food sections are also major foci. Recently, as the gap between the wealthy and the poor is increasing, and shopping patterns are changing accordingly, Korean department stores have made special efforts to attract VIP customers. While they have paid attention to the shopper side of the market, department stores have been less attentive toward shops. Different commission rates apply to the shops depending on the type of items they sell, their contribution to the store, and the value of the brand. Shops that do not match their sales goals may be evicted.

Because of our familiarity with the platform known as the department store, we tend to think of it as different from eBay, Google, Android, and iPhone. However, there is no difference between the department store and these IT-based platforms in the sense that all are connection chains.

\section{Economic Perspectives on Platforms}

Professor Jean Tirole, the Nobel Laureate in 2014, is a pioneer in the field of platform economics. The term "platform market", which is also called the two-sided market, means a market which connects more than two participants who benefit from its existence. Examples include video game consoles, credit cards, newspapers, shopping malls, and Google. One of the main characteristics of these platform markets is that participants on both sides have influence on each 
other's demands. In order to operate a video game platform, a sufficient number of games should be developed, and enough people have to use it. Advertisers are interested in how many subscribers a newspaper has as a measure of the effectiveness of advertisement in this medium.

This reciprocity in the platform market causes a problem: the price a platform imposes on one side influences the demands of the other side. For example, if credit card membership fees are expensive and there is no additional benefit from using that card, it is difficult to increase the number of users. In turn, the number of member stores will not increase. Alternatively, if the credit card fees for the stores are too expensive, very few stores will accept that card, and people will not want to use it.

When one side of the market is harder to attract than the other side, the platform determines the price for maximum profit. Sometimes subsidies are offered. Good examples include the case when a newspaper company charges less than the cost of production to its subscribers, or Microsoft sells the Xbox at the same or a lower price than its production costs. Its profits come from selling publishing rights to game developers or earning royalties from game sales. One final example: Google allows one side (users) to use its search engine for free while accepting payment from the other side (advertisers).

Professor Jean Tirole discusses what determines how much a platform charges its participants. The simplest business situation is the merchant market. In this case, demand is determined by the amount the company charges. However, the platform market is two-sided. Apple sells its customers iPhones, taking 30\% of App sales. In this case, how much Apple charges for the iPhone, the price of Apps, and other associated fees all determine the demand for iPhones and their Apps. In short, these two markets are connected.

The problem is simple if the platform sets a price for profit maximization in each market separately. However, the two-sided market is not that simple. The number of people who own iPhones is a significant determinant of how much an App developer invests in 
developing new iPhone Apps. In turn, the number of Apps consumers can use with the iPhone is a significant factor in their choice to buy the phone. It makes sense that companies reduce prices if they can increase demand by giving up some profit from one side or the other.

Professor Tirole also shows how the power or price of a platform influences the market. Traditionally in most countries, the practice of dumping has been restricted by the Fair Trade Act. When a company sells its products at a price lower than the production costs, it eliminates competitors. This is an effective practice for a company to eliminate competitors and to gain control over the market. Once the company gains control over the market, it will increase the price to recover the cost for dumping.

However, dumping works differently in the platform market. Newspaper companies distribute newspapers for free, not because they want to eliminate their competitors, but because they want to gain more revenue from advertisers by attracting more subscribers. In this case, dumping should perhaps not be restricted.

Applying the principle of the platform market, the best price is not always at the point where marginal costs and marginal profits meet. In the platform market, the price should be determined by considering how much it improves the well-being of the market as a whole.

\section{Platform: A New Business Model}

Platform strategy is different from traditional business strategy. The traditional business model is that the company produces goods and sells them. The platform business model, on the other hand, is that the company enlarges itself by improving the business ecosystem. The traditional business model focuses on the short-term pursuit of profit using a production and merchandising model. By contrast, the platform is a long-term business model focused on creating an attractive ecosystem and evolving within it.

The platform creates a playground, builds a market, and offers participants solutions in order to increase its user base. These 
solutions are often called the "invisible engine" of the platform, or the "killer contents". However, if the solution does not provide the participants with enough value, the platform loses its attractiveness. In addition, serendipity, or unexpected fun should be provided along with solutions in order to attract more users.

For example, Apple's iPhone provides a platform and an interface. Unlike companies that provide limited applications from suppliers, Apple provides a platform on which anyone can create App products. In addition, Apple created the App market, which had 300,000 participants within 30 months, and became the market leader. Apple grew fast in a short period of time because of the explosive expansion of the creative ecosystem of App developers based on the iPhone platform. This ecosystem provided solutions and serendipity to its users.

Apple was not complacent with this success, however; it expanded its business ecosystem through the development of an MP3 player, a music provider, and a docking audio system based on the iPhone. It also maximized value by reinforcing the interface and developing connecting software and hardware such as iTunes, the App Store, and the iPad.

Apple is an excellent example of how a company can succeed using the platform strategy. By creating a platform and focusing on its maintenance to provide a group interface on the playground, Apple became the leading company in its industry. It continues to expand the ecosystem with the development of other products, which will facilitate the evolution of the business.

\section{Insist on Piping or Transform into Platform?}

To understand what platform strategy is, we examine very different, existing business strategies. The concepts of openness, sharing, collaboration, and ecosystem, which are emphasized in platform strategy, are absent from what we in this book call "piping strategy".

Piping strategy entails the establishment of a network of pipes with a well-planned structural design. Traditional manufacturing companies in the 1970s are good examples. With this strategy, several essential things are planned ahead: how value will be created, and how 
products and services will reach customers through what kind of process. After planning, the company builds an infrastructure, and all business activities conform to this well-structured plan. This sticking to the well-structured plan is a fundamental difference between piping strategy and platform strategy. Platform strategy allows participants to collaborate with each other to redesign and develop new structures within the ecosystem, and all business activities contribute to the evolution of the ecosystem.

Another difference is that the plan developed through the piping strategy is exclusive. It is closed. Any attempt to change the plan without permission is like a criminal act, which is absolutely prohibited. In the traditional business model, if someone without a permit reprocesses the data, tries to reproduce the parts or products, or provides related or similar services, swift repercussions follow. By contrast, the platform encourages these behaviors.

In piping strategy, expansion of or changes in the network of pipes must happen under the control of the company based on its original plan. However, in platform strategy, any participant can expand or change the platform because the process of changes is a natural part of the evolution of the platform.

In the past, most businesses adopted the piping strategy not because they wanted to, but because they lacked understanding of platform strategy and because the piping model was more appropriate at the time. In the business environment of the past, planning and structuring was best executed by single companies alone. At the time, few technologies and resources were available, and the possibility of incorporating outsiders into the business was quite low. Even if it was possible, their contribution was quite limited. In addition, there was no appropriate means to monitor participants' activities to ensure the best business outcomes. These conditions led to the conclusion that it was more efficient for a capable company to establish its own infrastructure, allowing other companies to join in only as suppliers or subcontractors. Under these circumstances, participating companies could only execute the job demanded of them by the leading company. 
Circumstances have changed. In certain areas, individuals and small businesses have knowledge and capability similar to and competitive with those of large companies. Moreover, effective communication technology is available to facilitate smooth collaboration with outside participants. In this environment, it is more efficient to do business by inviting all available talents, both internal and external, to the company rather than doing everything alone. This is why the platform has appeared and why platform strategy has gradually replaced piping strategy.

Of course, not all businesses operating on the existing piping model will adopt platform strategy. Depending on the field and industry, piping can sometimes be a more appropriate model even in this new era. However, the reality is that the piping model will be replaced by the platform model more and more as time passes. As business people, we must therefore ask ourselves, in this changing business environment, whether we will stick to the piping model or change over to the platform model. 